\title{
Monitoring the Dynamic Behavior of PCI Bridges Using Short Period Seismograph and CSI Bridge Modeling
}

\author{
Said Jalalul Akbar, Maizuar*, Khairullah Yusuf, Joni Arfiandi \\ Department of Civil Engineering, Universitas Malikussaleh, Aceh, Indonesia \\ *Corresponding author E-mail: maizuar@unimal.ac.id
}

\begin{abstract}
Manuscript received 15 August 2021; revised 1 Sept 2021; accepted 15 Sept 2021. Date of publication 4 Nov 2021

Bridges are a critical part of transport infrastructure networks for social activities and economics of human life. Dynamic analysis of bridge is very important to perform in order to ensure the ability of the bridge to withstand loads and maintain the sustainability of transport infrastructure. This paper presents a methodological framework for monitoring dynamic behavior of the bridge (e.g., natural frequencies, displacement time history) by using civil engineering micro-tremor technique and numerical modeling. The study was conducted at the Alue Raya Bridge located in Lhokseumawe City, Aceh Province, Indonesia. To capture the dynamic behavior of the bridge under traffic loading, the micro-tremor techniques, e.g., Short Period Seismograph (SPS) sensor was placed underneath the bridge at the mid span of the bridge girder. The obtained vibration data were processed using Geopsy software. A three dimensional (3D) model of the bridge was then developed by using CSI Bridge software. The modal analysis was conducted to obtain the modal natural frequencies of the bridge due to traffic loads. The natural frequency measurements using SPS were compared with the simulation results. Through analyzing the measured results, it was found that the natural frequency of the bridge is around 4,3275 $\mathrm{Hz}$ which is very close to those obtained from numerical modeling using CSI bridge software. The measured maximum vertical displacement of the bridge girders is below $5 \mathrm{~mm}$ under normal traffic condition which is under the allowable serviceability limit state requirements of the bridge. The outcomes of this study could have the potential to enable maintenance and capital works decisions which are an important component of the sustainability of transport infrastructure.
\end{abstract}

Keywords: Dynamic Behavior, Bridge, SPS, CSI Bridge, Natural Frequency.

\section{Introduction}

Bridge is one of the important infrastructures for social and economic activities of human life. Therefore, investment in bridge infrastructure has increased significantly in recent decades [1], [2]. The bridge development reflects the latest advanced in science and technology. A bridge is a construction that is located above the surface of water or land, connecting one place to another which is separated by physical obstacles such as rivers, seas, railways, heavy traffic and others. Bridge infrastructure must be constructed with sufficient strength in order to withstand higher loads during the service live period.

Based on statistical data, the total length of bridges in Indonesia is around 537,991.2 km. The recent condition assessment of bridges had been rated structurally deficient with $57.20 \%$ of them are in good condition, $31.34 \%$ in moderate condition, $8.57 \%$ in minor damaged condition, $1.68 \%$ in severely damaged condition, and $1.21 \%$ in a collapsed condition [3]. Further, the increased structural deterioration of bridges is more vulnerable to ageing bridge infrastructures under the increase traffic loads which could led to the reduced service life of bridge structures [4].

Bridge condition assessments using vibration measurement (e.g., accelerometer) with the aim of detecting damage on concrete bridges are required to ensure adequate maintenance and repair measures can be taken [5]. Vibration measurement can be used to estimate and monitor the bridge dynamic characteristics such as natural frequency, mode shape and bridge displacement caused by dynamic loads (e.g., traffic loads). Such dynamic characteristics are can be obtained by using micro tremors technique (e.g., Short Period Seismograph) [6]. Short Period Seismograph (SPS) is a vibration sensor that is commonly used to detect earthquakes or vibrations on the ground surface. This tool is very sensitive to seismic waves generated by earthquakes, nuclear explosions and other sources of seismic waves. This concept makes SPS a tool in obtaining data of natural frequencies and bridge displacement.

The natural frequency of a structure is affected by the stiffness and mass of the structure. The value of the natural frequency of a structure will remain constant unless the structure undergoes damage due to changes in the stiffness and mass of the structure. Thus, the natural frequency is a good indicator of the assessment of the damage experienced by a structure [7]. Further, natural frequency can be used as a 
measure whether a structure experiences resonance or not. A structure will experience resonance if the value of the frequency of the structure is close to or equal to its natural frequency [8].

Assessing the bridge dynamic characteristics under traffic loads in operational condition is time-consuming and requires a large amount of resources. In this context, many researchers have developed numerical modeling to estimate bridge dynamic characteristics (e.g., CSI Bridge) and the obtained simulation results were then compared and validated with experimental tests [7], [9]. CSI Bridge is a specialized analysis and design software used for bridge analysis and design. Furthermore, CSI Bridge simulation software has become increasingly popular in modeling reinforced concrete bridge structures [10]. The software provides options for static and dynamic analyses as well as modal and buckling analyses. Therefore, the objective of this study is to develop a methodological framework for monitoring dynamic behavior of the bridge (e.g., natural frequencies) by using micro-tremor techniques (e.g., SPS) and numerical modeling.

\section{Methods}

\subsection{Natural Frequency}

Natural frequency is defined as vibrations that occur in structures without any force affecting the structures. This condition is referred to free vibration. In the field tests, the natural frequency of the structure can be obtained by installing a sensor device on the structure (e.g., SPS). The measured vibration data is used to determine the natural frequency of structures. If a structure having a mass of $m$ and stiffness of $k$, the natural frequency, $f$, can be determined by:

$$
f=\frac{1}{2 \pi} \sqrt{\frac{k}{m}}
$$

\subsection{Mode Shape}

A mode shape is a pattern of vibrations produced by a system at certain frequency. It also can be seen as the deformation of the structure when it vibrates at the natural frequency. It is therefore, the vibration and deformation occur when an excitation is given on a structure. At each frequency, the mode shape of the system is definitely different. The result of the total vibration of a structure is usually determined as the summation of the individual vibration shapes.

\subsection{Displacement}

Displacement is a change or deformation of a structure due to any given loads (Figure 1). For example, an earthquake or traffic loads could induce displacement in the bridge structure. Depending on this excitation, the displacement of a structure may experience small or excessive displacement. It have been known that excessive displacements in concrete bridge structures may resulted in concrete cracks, cause other damage, and can be unsafe. Therefore, the maximum displacement of the bridge should not exceed the allowable serviceability limit state requirements of the bridge (e.g., L/400).

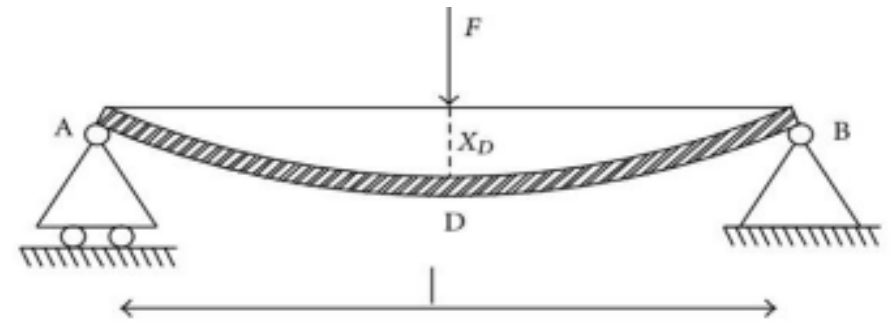

Fig 1. Displacement of a beam under concentrated load [11]

The study was conducted at the Alue Raya Bridge located in Lhokseumawe City, Aceh Province, Indonesia as shown Figure 2 and 3 . The simple-span prestressed concrete bridge was built in 1989, with a length of $25.5 \mathrm{~m}$ and width of $8.75 \mathrm{~m}$. This bridge was recently upgraded to accommodate the increased amount of traffic and to reduce traffic congestion during peak periods. After this extension, the bridge consists of two lanes in each direction. The bridge deck is supported by five PCI girders on abutments at two extreme ends of the bridge. The geometric and material properties of the Prestressed Concrete I (PCI) girder were shown in Figure 4 and 5. 


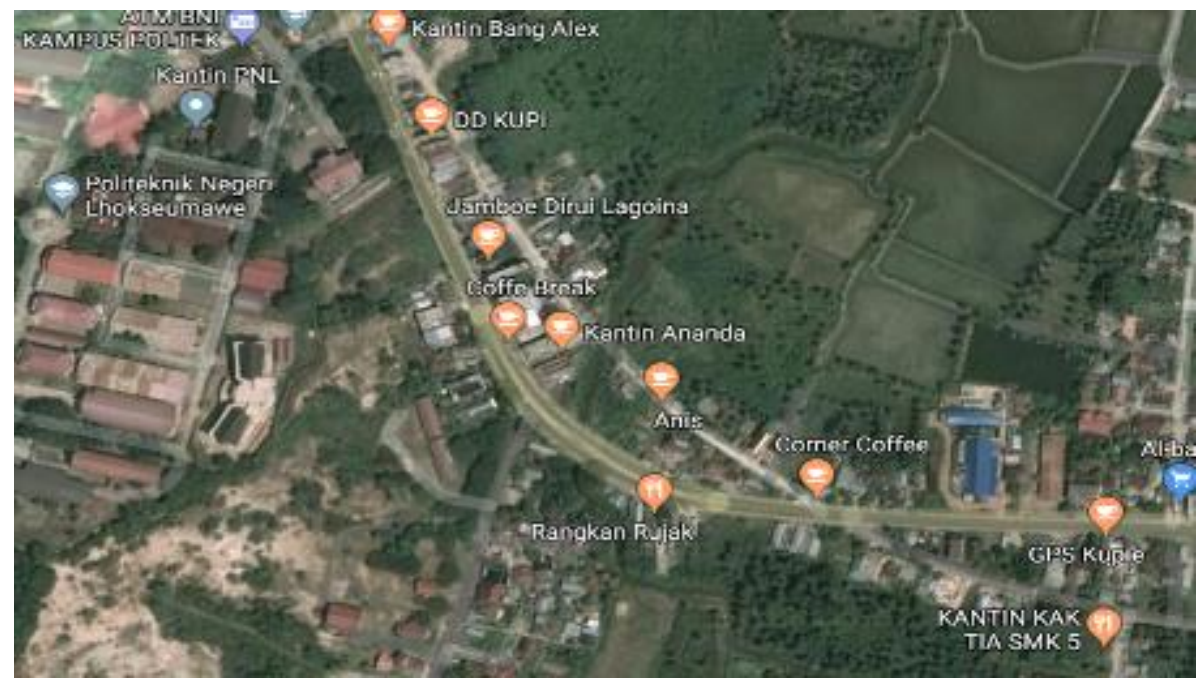

Fig 2. Location of the Alue Raya Bridge

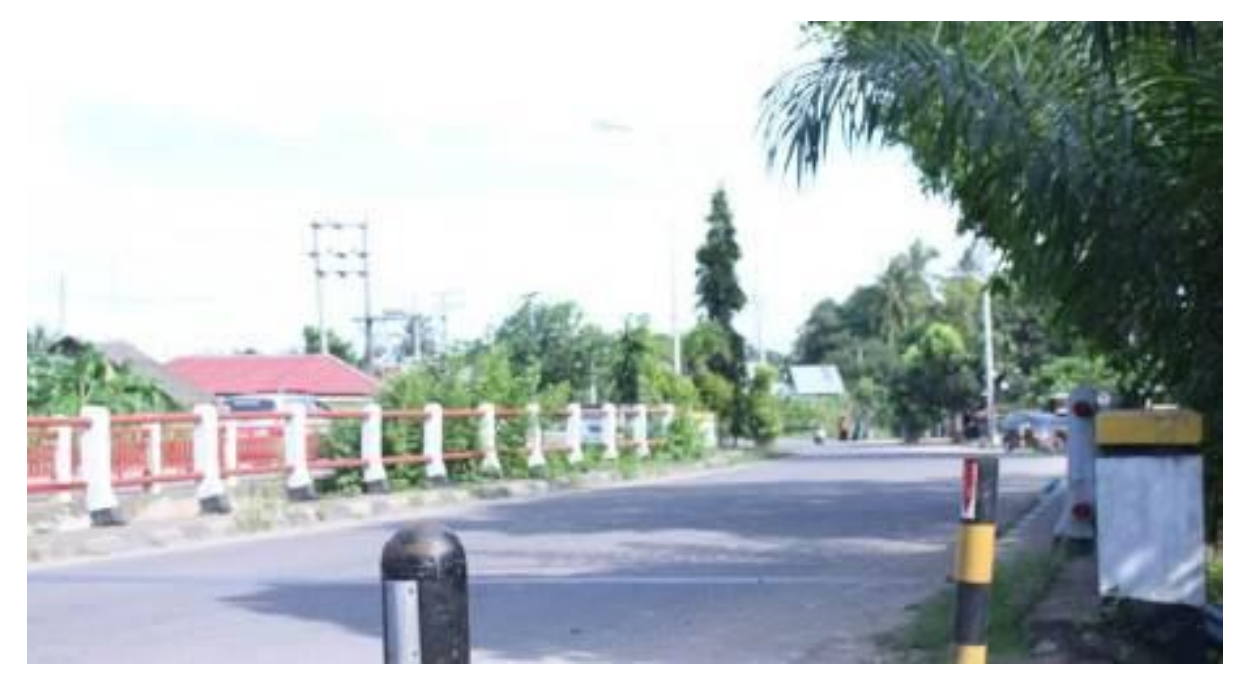

Fig 3. View of the Alue Raya Bridge

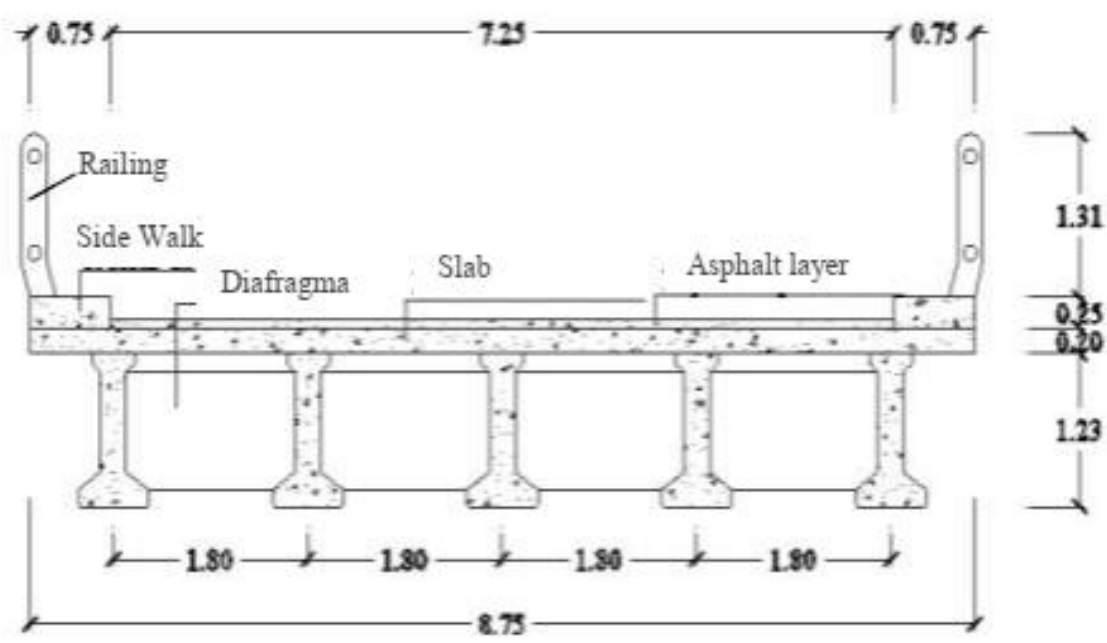

Fig 4. Elevation view of the bridge 


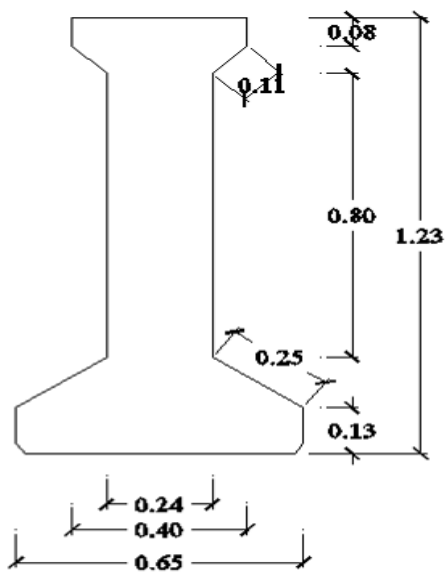

Fig 5. Detail of PCI girder

To capture the dynamic characteristics (e.g., displacement time history, natural frequency) of the bridge under traffic loading, the SPS sensor was placed underneath the bridge at the mid span of the bridge. The SPS components consist of sensors, digitizers, GPS, power supplies and data storage systems. The sensor captures vibration waves in the form of physical quantities. The SPS has two types, namely short period and broadband. In this study, the type of SPS used was a short period of Lennartz Electronic Type LE-3Dlite Mkll 223-0041 as shown in Figure 6.

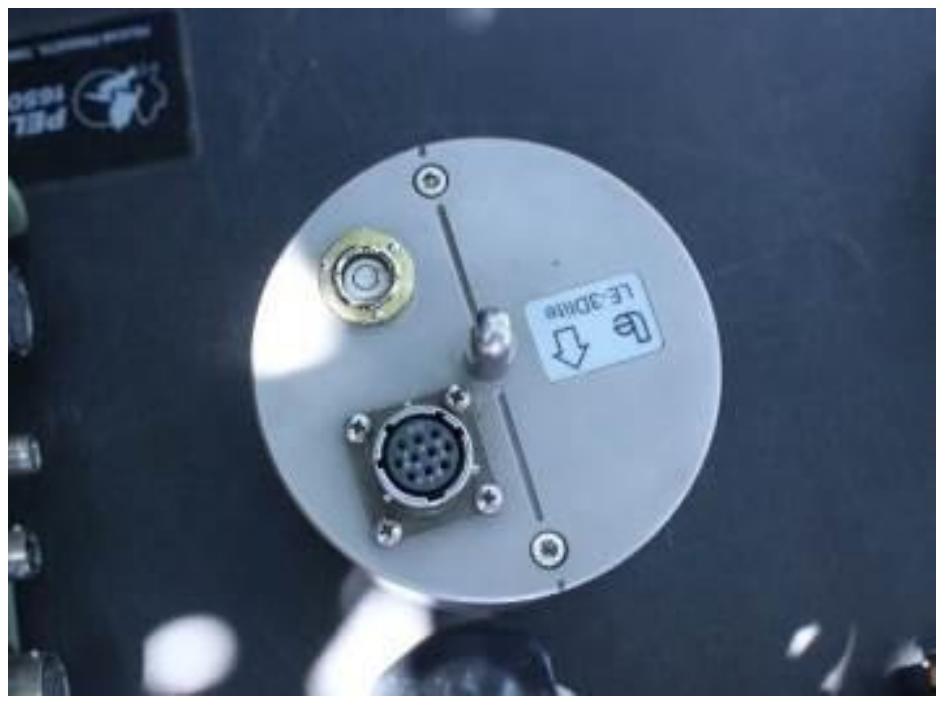

Fig 6. View of SPS sensors

The SPS sensor records vibration data resulting from vehicle loads and then sent to a digitizer. Vibration data received in the digitizer were processed in data output that can be read on a computer or laptop. The GPS provides information about the coordinates of the sensor position. Electric power sources can be obtained from a battery or solar panel.

Vibration waves captured by SPS cannot be processed by the Analog to Digital Converter (ADC). It is required to be amplified and filtered by a signal amplifier. The result of the signal conditioning (amplifier) is the input for the ADC. The combination of the signal amplifier and ADC is called a digitizer. The digitizer is also integrated with a data logger as data storage. In this study, the Taurus digitizer produced by Nanometric was used (Figure 7). 


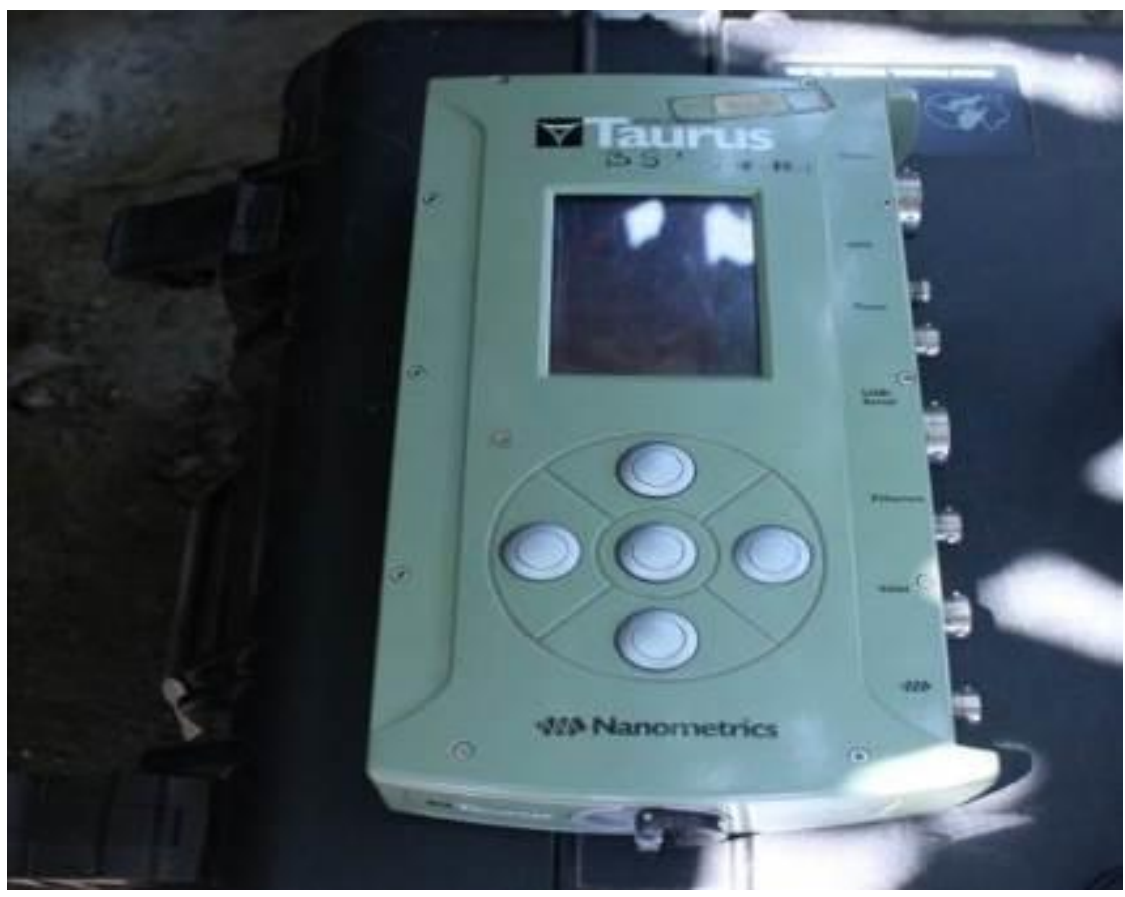

Fig 7. View of Taurus Digitizer

The obtained vibration data in time domain can be converted into frequency domain using Fast Fourier Transform (FFT) [12]. In this study, the FFT conversion was performed by using Geopsy software. The Geopsy is geophysical software which provides tools for processing ambient vibrations. The data from FFT which turns into a frequency domain is also known as Frequency Response Function (FRF). In the FRF curve, the natural frequency of the structure of each mode is associated with the peak frequency of the curve. FFT can be defined as follows:

$x_{(\omega)}=\int_{-\infty}^{\infty} x_{(t)} e^{-i \omega t} d t$

Where:

$$
\begin{aligned}
& x_{(t)}: \text { Signal function in time domain } \\
& \boldsymbol{e}^{-\boldsymbol{i} \omega t}: \text { Kernel function } \\
& x_{(\omega)}: \text { Signal function in frequency domain }
\end{aligned}
$$

The measurement results from SPS were compared with results from CSI Bridge software version 19.0.0.

\section{Results and Discussion}

Vibration data obtained from SPS was transferred to a computer or laptop and then analyzed using Geopsy software to obtain the natural frequency of the bridge. The measurements were conducted three times and the results of natural frequencies are shown in Table 1, Figure 8, Figure 9 and Figure 10. As shown in Table 1, the average of the bridge natural frequency using SPS is $4,3275 \mathrm{~Hz}$.

Table 1. Bridge natural frequencies results using SPS

\begin{tabular}{ccc}
\hline Test No. & Time & Frequency $(\mathrm{Hz})$ \\
\hline 1 & $14.30-15.00 \mathrm{WIB}$ & 4,3256 \\
2 & $16.30-17.00 \mathrm{WIB}$ & 4,3215 \\
3 & $17.30-18.00 \mathrm{WIB}$ & 4,3355 \\
\hline
\end{tabular}




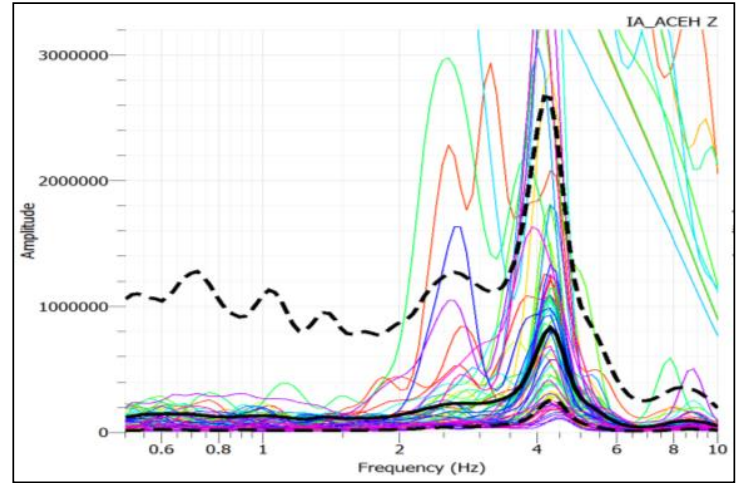

Fig 8. Bridge natural frequency of test 1

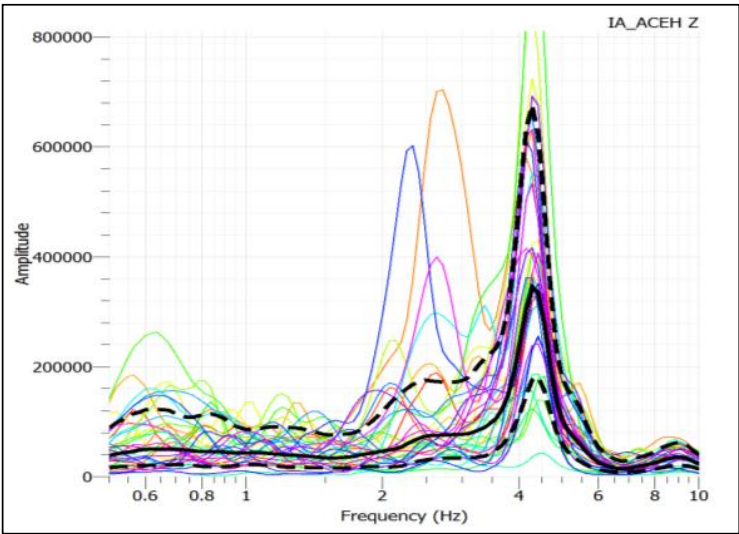

Fig 9. Bridge natural frequency of test 2

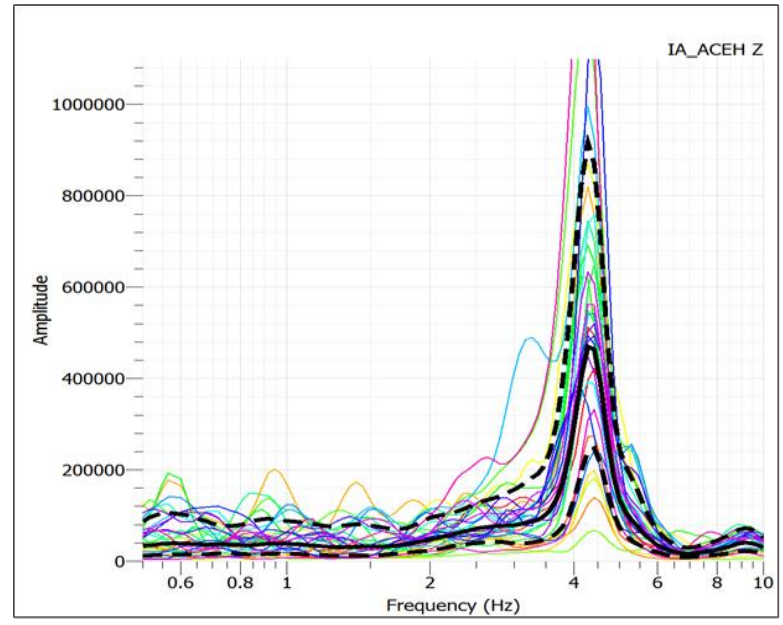

Fig 10. Bridge natural frequency of test 3

The measurement results can be further processed to obtain the bridge displacement using DADISP software. DADiSP computes and visualizes data that combines the power of programming with the simplicity of a spreadsheet. The measurement data is exported in the form of ASCII one column (no header) data so that it can be read on the software for further analysis. The maximum displacement of the bridge obtained under normal traffic condition is around $0.5 \mathrm{~cm}$ as shown in Figure 11. The results indicate that the structural integrity of the bridge is in good condition. The observed maximum vertical displacement is also under the allowable serviceability limit state requirements of the bridge (e.g., L/400). 


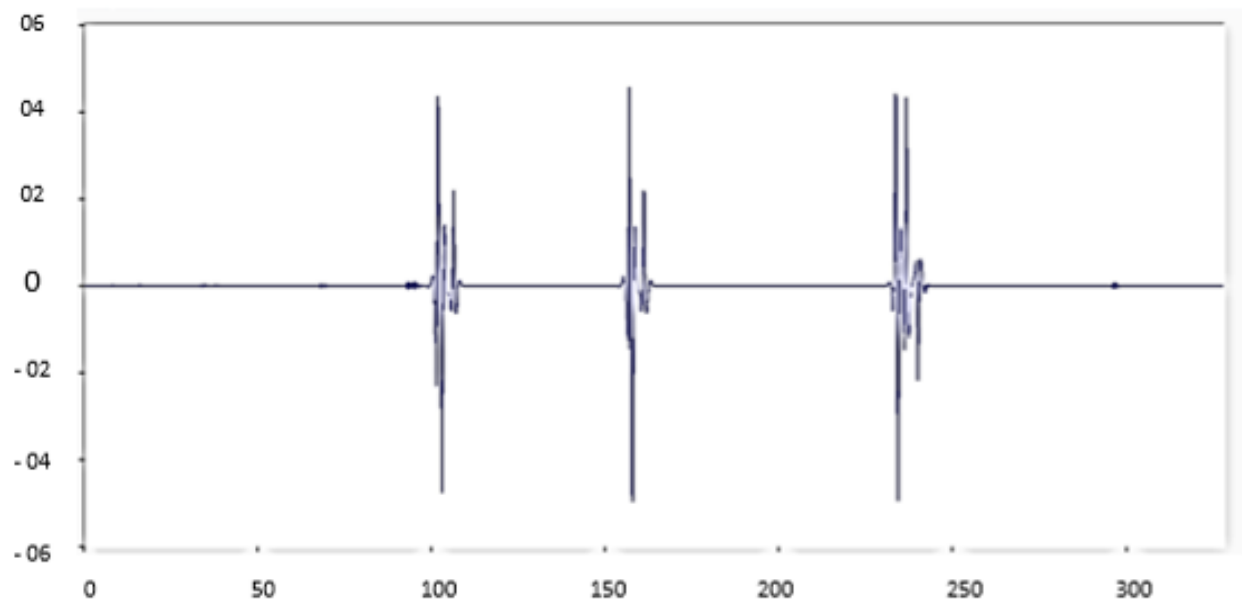

Fig 11. The displacement profile of the bridge under normal traffic condition

A three dimensional (3D) model of the bridge was developed by using CSI Bridge software. The modal analysis was conducted to obtain the modal natural frequencies of the bridge due to traffic loads. The natural frequency depends on the mass and stiffness of the structure. For two systems with the same mass but different stiffness, the system with the larger stiffness has a higher natural frequency and a shorter period of vibration. If two structures have the same stiffness but different masses, the system with the larger mass has a smaller natural frequency and a longer period of vibration. The result of the natural frequency obtained from CSI Bridge is $4.021 \mathrm{~Hz}$. It can be seen that numerical modeling result is close to those obtained from the SPS measurements.

There are three mode shapes of the bridge using the modal analysis of the CSI Bridge: transverse direction, vertical direction and the longitudinal direction of the bridge. Mode shape is a pattern of vibrations produced by a system at a certain frequency. At each natural frequency of the bridge, the mode shape produced by a system must be different. The mode shape of the bridge structure in this study only shows the first 3 modes as given in Figure 12 to Figure 14.

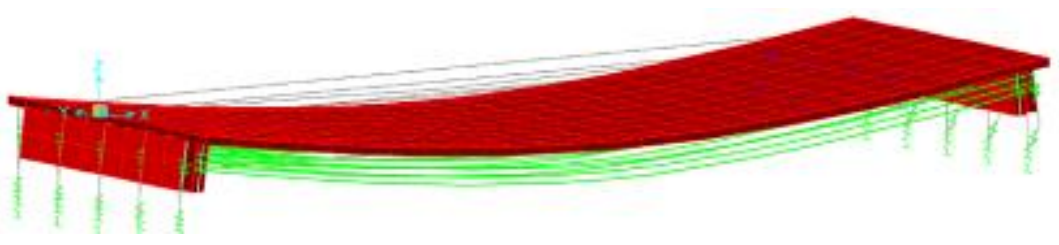

Fig 12. The $1^{\text {st }}$ Mode Shape of the bridge

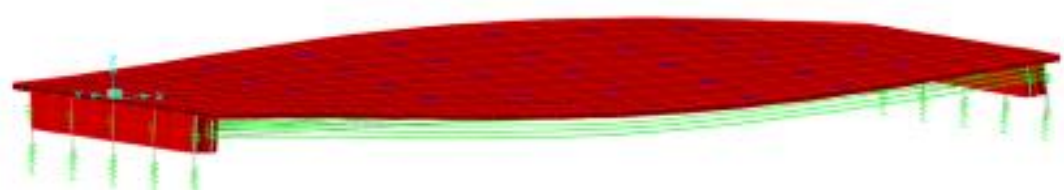

Fig 13. The $2^{\text {nd }}$ Mode Shape of the bridge

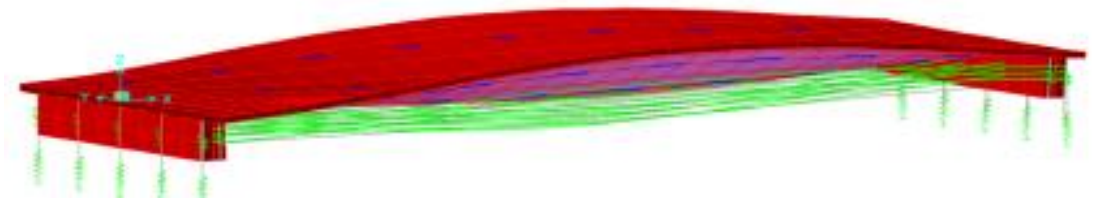

Fig 14. The $3^{\text {rd }}$ Mode Shape of the bridge

\section{Conclusion}

In this study, the dynamic behavior of the Alue Raya PCI bridge girders under traffic loads was monitored using the SPS measurement techniques. The experimental tests were then compared and validated with simulation results. Through analyzing the measured results, it concludes that the natural frequency of the bridge is around $4,3275 \mathrm{~Hz}$ which is very close to those obtained from numerical modeling using CSI bridge software. The maximum vertical displacement of the bridge girders is generally below $5 \mathrm{~mm}$ under normal traffic condition which is under the allowable serviceability limit state requirements of the bridge. 


\section{Acknowledgement}

The authors wish to thank BMKG Stasiun Geofisika Banda Aceh, Balai Pelaksanaan Jalan Nasional-I Aceh, LPPM Universitas Malikussaleh, David Firnando, Sri Ganti, Firman Hidayat and Agem Neneng Kasmiani for their support.

\section{References}

[1] Maizuar, S. J. Akbar, Wesli, and Burhanuddin, "Reliability-based approach for residual life prediction of bridges subjected to earthquake shocks degradation,” Teras Jurnal-Jurnal Tek. Sipil, vol. 9, no. 1, pp. 63-70, 2019.

[2] Maizuar, L. Zhang, R. Thompson, and H. Fithra, "Life-Cycle Performance of a Bridge Subjected to Multiple Heavy Vehicle Impacts," in Proceedings of MICoMS 2017, vol. 1, Emerald Publishing Limited, 2018, pp. 13-18.

[3] PUPR, "Buku Informasi Statistik 2017," Kementeri. Pekerj. Umum dan Perumah. Rakyat Sekr. Jenderal Pus. Data dan Teknol. Inf. (Pusdatin), Jakarta, 13p, 2017.

[4] Maizuar and S. J. Akbar, "Dynamic monitoring of bridges: accelerometer Vs microwave radar interferometry (IBIS-S)," in Journal of Physics: Conference Series, 2021, vol. 1882, no. 1, p. 12124.

[5] Maizuar, S. J. Akbar, and Salahuddin, "Developing a low-cost vibration measurement system prototype for bridges using accelerometer sensors: A review," Int. J. Psychosoc. Rehabil., vol. 24, no. 2, pp. 12-19, 2020

[6] M. Kaloop, M. Elsharawy, B. Salah, J. Hu, and D. Kim, "Performance Assessment of Bridges Using Short-Period Structural Health Monitoring System: Sungsu Bridge Case Study," Smart Struct. Syst., vol. 26, pp. 605-617, Nov. 2020, doi: 10.12989/sss.2020.26.5.667.

[7] M. Maizuar, L. Zhang, S. Miramini, P. Mendis, and R. G. Thompson, "Detecting structural damage to bridge girders using radar interferometry and computational modelling," Struct. Control Heal. Monit., vol. 24, no. 10, p. e1985, 2017.

[8] L. Zhang, M. Maizuar, P. Mendis, C. Duffield, and R. Thompson, "Monitoring the Dynamic Behaviour of Concrete Bridges Using Non-Contact Sensors (IBIS-S)," Appl. Mech. Mater., vol. 846, pp. 225-230, Jul. 2016, doi: 10.4028/www.scientific.net/AMM.846.225.

[9] B. Kafle et al., "Monitoring the Dynamic Behavior of The Merlynston Creek Bridge Using Interferometric Radar Sensors and Finite Element Modeling," Int. J. Appl. Mech., vol. 09, no. 01, p. 1750003, Dec. 2016, doi: 10.1142/S175882511750003X.

[10] L. Kottalil, M. M. Sabu, M. S. Mathew, and M. Pavanan, "Study on Cable Stayed Bridge using CSiBridge Software," 2019.

[11] A. Gimelli, A. Rapicano, F. Barba, and O. Pennacchia, "Reciprocating Compressor 1D Thermofluid Dynamic Simulation: Problems and Comparison with Experimental Data," Int. J. Rotating Mach., vol. 2012, Jun. 2012, doi: 10.1155/2012/564275.

[12] Y. B. Yang, "Measuring the bridge frequencies from the response of a passing vehicle," in Environmental Vibrations: Prediction, Monitoring, Mitigation and Evaluation: Proceedings of the International Symposium on Environmental Vibrations, Okayama, Japan, September 20-22, 2005, 2021, p. 173. 